\title{
EDITORIAL
}

\section{Jail segregation today, hospital seclusion tomorrow}

\author{
Gary Chaimowitz ${ }^{1,2}$
}

\author{
1 McMaster University, Department of Psychiatry \\ and Behavioural Neurosciences, Hamilton, Canada \\ 2 St. Joseph's Healthcare Hamilton, Forensic \\ Psychiatry Program, Hamilton, Canada
}

Gary Chaimowitz is a Professor of Psychiatry at McMaster University and the Head of the Forensic Psychiatry Program at St. Joseph's Healthcare Hamilton. Among many roles, Professor Chaimowitz has been granted Forensic Psychiatry Founder Status. He is one of the creators the Hamilton Anatomical Risk Management (HARM) and the Aggressive Incident Scale (AIS). Professor Chaimowitz is the Editor in Chief of the International Journal of Risk and Recovery.

There has been a lot of attention given to the use of segregation in correctional facilities, sufficient that a number of class action lawsuits have been launched, and in many cases, they have been settled. Psychiatrists and psychiatry in general have mostly watched these issues play out from the sidelines. Segregation occurs in correctional facilities and few psychiatrists work in jails and prisons. Although mental health professionals watched with interest and concern, it remained an issue in correctional settings, not in our house. In the last few decades psychiatry has done a lot of work in reducing seclusion in hospitals. The tracking of seclusion, the requirements for reassessment and seclusion justification, along with improved training of staff about the traumatic effects of seclusion have helped in reducing seclusion rates and the length of individual seclusions. Psychiatry has done well in this regard and hence it would not be surprising that many may think that the issues associated with seclusion have been dealt with. This may be an error for the following reasons.

Psychiatry continues to evolve and so do our views of a whole multitude of "psychiatric" issues. There was a time in medicine where clinicians failed to recognize the impact of their behaviour on patients, and may have failed to consider the patient's experience, particularly inpatient's. Clinicians also did not recognize the impact of certain procedures on the people they cared for. It is only in the more recent years that we have begun to recognize the deleterious effects of certain clinical practices. For example, in jails inmates were segregated and in psychiatric settings they were secluded without a full appreciation of the harmful effects.

Over time most mental health professionals have come to understand that solitary confinement/segregation has harmful effects on inmates with major mental disorders. Apart from the need to place highly agitated and violent mentally ill inmates in a secure/segregated setting for a brief period of time, there are no other specific situations where one could justify the use of extended segregation for mentally ill people because of their mental illness, without the provision of active psychiatric treatment (as the vast majority of correctional settings are not clinical) $[1,2]$. The correctional environment has not been able to celebrate the advances that the hospital sector made in the reduction of seclusion for many reasons, including the very different systems, the physical structure, staff skillsets, and very different foci/purposes.

All the while there has been a growing consensus and increasing awareness among mental health professionals of the deleterious effects of extended periods of isolation on people generally, but certainly on people with major mental illness. Psychiatric institutions have done enormous work in reducing their equivalent of solitary confinement, namely seclusion, given the increasing understanding of the deleterious effects of this intervention. But as the lights go on around us, the question is going to be whether this is enough? 
When it comes to correctional settings, there are studies that identify the psychological consequences of the isolation of solitary confinement, and more researchers have recognized the effects of solitary confinement in people with serious mental illness, exacerbating their illness, or even provoking another illness episode [37]. It has been argued that the research is not perfect but the signals received from what has been done has been compelling. The effects of solitary confinement are well described by a number of authors such as Grassian, Lobel, Arrigo and others [3-5]. Segregation in Canadian contexts has recently been reviewed independently [8]. The harmful effects have not only been well described in the literature over many years, but are also sufficiently well known that people have linked extended solitary confinement to the idea that it approximates some form of torture. In a U.S. case, Madrid v. Gomez, 889F. Supp. 1146, 1265 (ND Cal. 1995), the judge commented that putting mentally ill prisoners in isolated confinement is "the mental equivalent of putting an asthmatic in a place with little air" [9].

Historically, isolation from society is a form of punishment [3]. Jailing people has a punishment aspect to it. Torture has used aspects of isolation and sensory deprivation, breaking down resistance and breaking will [3]. Solitary confinement is associated with the absence of the ability to interact with others and not being exposed to the usual stimuli and experiences in everyday life [3]. The clinical view would then be that ill individuals in solitary confinement should be either treated or moved quickly to a mental health facility where assessment and further treatment could be provided [4]. Jails and prisons are considered ill equipped to manage acutely psychotic individuals.

The effects of solitary confinement are significant enough that they have been considered as cruel and inhuman treatments that can damage the person and impact their dignity [3-7]. This is in addition to the ongoing corrosive effect of solitary confinement on somebody with a major mental disorder. Several international organizations and human rights groups have described extended solitary confinement as torture [10-12]. The growing recognition that solitary confinement is cruel and inhuman captures the general view of the damaging effects and psychological harm attached to solitary confinement [12].

Numerous initiatives have been established to reduce, and in some cases eliminate, seclusion [1,2]. Any extended period of psychiatric seclusion for active mental illness when individuals pose a risk to others is closely monitored, restricted, and considered something that requires close oversight. We have learnt that many psychiatric patients have trauma histories and secluding them can reactivate and further traumatize them [11]. In correctional environments we know that many inmates including those without major psychiatric illnesses have trauma histories and are even more susceptible to the negative effects of segregation [11].

Unfortunately, major changes occur under threat or after negative events. Deaths in custody, Coroners cases, violent events, and lawsuits drive change, probably more than altruistic initiatives [2]. Notwithstanding the tremendous advances psychiatry has made in reducing seclusion, in 2020, the current state may not be enough in the future.

Seen through modern lenses, seclusion rooms in hospitals are not nice places. Even modern builds have limited light, substandard ablution and washing facilities, and few opportunities for fresh air (that even people in segregation have) [2]. Given what is now possible with architecture and technology, one may ask the question: if seclusion as we know it is necessary (and the question will be if it is really necessary), can we do a better job about how we reduce the traumatic effects of separating people from society? Perhaps when the lawyers are finished with segregation in corrections, they will turn their attention to seclusion in hospital. Or will we have the foresight to address the conditions of seclusions before the lawsuits arrive? 


\section{References}

1. Annual report of the office of the Correctional Investigator 2014-2015. (accessed on December 30, 2019)

2. Annual report of the office of the Correctional Investigator 2015-2016. (accessed on December 30, 2019)

3. Grassian, S. Psychiatric effects of solitary confinement. Wash UJL \& Pol'y 2006;22(1):32583

4. Arrigo BA, Bullock JL. The psychological effects of solitary confinement on prisoners in supermax units: reviewing what we know and recommending what should change. Int J Offend Therapy 2007;52(6):622-40

5. Lobel J. Prolonged solitary confinement and the Constitution. U Pa J Const L 2008;11(1):115-38

6. Gordon SE. Solitary confinement, public safety, and recidivism. U Mich JL Reform 2014;47(2): 495-528

7. Pizarro J, Stenius VMK. Supermax prisons: their rise, current practices, and effects on inmates. Prison J 2004;84(2):248-64

8. Segregation in Ontario: independent review of Ontario corrections. Toronto: Queen's Printer for Ontario, 2017. (accessed on December 30, 2019)

\section{Corresponding author}

Gary Chaimowitz, Forensic Psychiatry Program, St. Joseph's Healthcare Hamilton, Hamilton ON L9C 0E3, Canada - email: chaimow@mcmaster.ca
9. Madrid v. Gomez, 889. F. Suppl.1146 1230-32 (N.D. 1995). (accessed on December 30, 2019)

10. Human Rights Watch. Written statement to the Committee on the Judiciary, Subcommittee on the Constitution, Civil Rights and Human Rights. December 9, 2014. (accessed on December 30, 2019)

11. Ayan A, Baykal T, Beynon J, Dromer C, Korur Fincancı S,Gautier A et al. (Task group participants). The Istanbul statement on the use and effects of solitary confinement adopted on 9 . December 2007 at the International Trauma Symposium, Istanbul. Torture 2008;18(1):63-6

12. Méndez RJ (Special Rapporteur of the Human Rights Council, United Nations). Torture and other cruel, inhuman, or degrading treatment or punishment (interim report). Resolution A/66/268. 5 August 2011. (accessed on December 30, 2019) 